\title{
SERENDIPIA Y MICROBIOLOGÍA
}

\author{
Fernando Quevedo Ganoza
}

$E^{n}$ $\mathrm{n}$ el Editorial de "Ciencia e Investigación" (Vol. VIII, la Investigación Científica en la Facultad de Farmacia y Bioquímica de la UNMSM", ofrecimos presentar uno o más artículos que revisaran, comentaran y transcribieran las informaciones tomadas de tres publicaciones que se ocuparon de Serendipia y descubrimientos científicos en Química, Microbiología y Farmacología. En esta oportunidad, nos ocuparemos de Serendipia y Microbiología, basándonos en los artículos publicados por los Drs. Francisco Hernández y Patricia Rivera, colegas de Costa Rica, y del Dr. Antonio Zarzuelo, de la Academia Iberoamericana de Farmacia, del Instituto de Andalucía, España.

Por supuesto que, tal vez, el episodio de Serendipia y Microbiología (y Farmacología) más conocido y divulgado es el de Alexander Fleming. Nos recuerda el Prof. Zarzuelo que «Fleming nació en una región rural y remota de Escocia en 1881. Cuando estalló la guerra de los Borres, entre Gran Bretaña y las colonias del África Austral, se incorporó a un regimiento escocés, donde si bien no participo en ninguna acción, tuvo oportunidad de practicar sus habilidades de tiro, lo cual fue fundamental en el descubrimiento de la penicilina».

Los Drs. Hernández y Rivera opinan que «Posiblemente Alexander Fleming no era el dechado de orden y limpieza que esperamos de un microbiólogo moderno en el laboratorio. En 1922, encontró un principio bacteriolítico en las secreciones lacrimales y nasales cuando, estando resfriado, consciente o accidentalmente contaminó con sus secreciones nasales un plato de cultivo donde crecían colonias de Staphylococcus y encontró que las bacterias eran destruidas. A ese principio lo llamó lisozima y en pos de su purificación y caracterización trabajo por mucho tiempo, por lo que su laboratorio estaba atestado de platos de Petri con cultivos de las bacterias de sus experimentos; pero estos se acumulaban, ya que no acostumbraba a descartar con frecuencia los platos examinados... »

El Dr. Zarzuelo aporta algunos datos adicionales, y también nos dice que Fleming «....hacia tantas cosas a la vez y era tan desorganizado, que lo normal era que en su laboratorio reinara el desorden, un desorden que al final resultó providencial».

También nos relata el Dr. Zarzuelo que Fleming dijo una vez, «No esperes que la fortuna te sonría: prepárate con el conocimiento». De alguna manera, todo lo que el mismo había hecho hasta este momento puede considerarse parte de esa preparación, para lo que vendría después. En los últimos días del verano de 1928, cuando se fue de vacaciones, por alguna razón se le olvido guardar sus cultivos de Staphylococcus en las estufas, dejando las placas Petri sobre la poyata. Llegados a este momento, vale la pena explicar un poco como era la disposición del laboratorio. Como a Fleming le era casi imposible abrir la ventana, solía dejar la puerta abierta para que circulara un poco de aire; dicha puerta daba a un tramo de escaleras y en el piso de abajo había otro laboratorio que estaba siendo utilizado por un joven micólogo irlandés, C. J. La Touche, cuya puerta se abría al mismo tramo de la escalera, y que por entonces estaba trabajando con varias cepas de diferentes hongos. Su laboratorio carecía de campana de gases, cosa que le hubiera permitido confinar las esporas del hongo en una pequeña área aislada. Por la falta de campana, las esporas se extendieron por todo el laboratorio del micólogo y después fueron arrastradas por el aire a través de la puerta abierta y, escaleras arriba, subieron hasta que encontraron el camino hacia el laboratorio de Fleming".

Cuando Fleming regresó de sus vacaciones en septiembre, empezó a desechar algunas de las placas Petri que había dejado fuera de la estufa. De ordinario, la contaminación es la maldición del trabajo del bacteriólogo. Cuando un cultivo está contaminado, normalmente el primer impulso de un científico es desecharlo y empezar de nuevo. Esto es lo que Fleming se dispuso a hacer en una especie de limpieza general rutinaria, pero de nuevo intervino el azar. En aquella época, el Departamento de Inoculación del St. Mary utilizaba contenedores de eliminación esmaltados bajos con muy poco antiséptico (si el de Fleming hubiera sido un laboratorio bacteriológico bien equipado, habría tenido cubos profundos llenos de antiséptico hasta el borde). Fue entonces cuando, después de haber tirado los cultivos contaminados, observó un halo claro que rodeaba las colonias amarillo verdosas del hongo que había contaminado accidentalmente la placa.

Fleming escribió: «era sorprendente que a una distancia considerable alrededor del crecimiento del hongo, las colonias de estafilococos mostraron lisis. Lo que antes había sido una colonia bien desarrollada era ahora una tenue sombra de lo que fue». Dedujo que el hongo debía de haber liberado una sustancia que simultáneamente destruyó las bacterias existentes e inhibió su crecimiento posterior. Vemos por tanto que fue necesario un cúmulo de casualidades para que se produjera este feliz descubrimiento. Pero todo ello necesitó de la mente observadora de Fleming para que se diera cuenta del importantísimo hallazgo. El mismo comentó «Hay miles de mohos diferentes y miles de bacterias diferentes, y el que el azar haya puesto el moho en el sitio correcto, en el momento correcto, ha sido como ganar a los irlandeses arrasando. Mi único mérito es que no pasé por alto la observación y que seguí el tema como bacteriólogo».

Lo que siguió en la historia de la penicilina es bastante conocido. Todo fue producto de la Serendipia. Es decir, y sobretodo, de un espíritu científico bien preparado.

Otro ejemplo de muy bien explicado por los Drs. Hernández y Rivera, es el ahora ya famoso descubrimiento de la localización de Helicobacter pylori en la mucosa gástrica y su efecto patogénico.

Personalmente recuerdo que, cuando era estudiante universitario, tuve la suerte de ser ayudante de la Cátedra de Bacteriología y Parasitología, a cargo de los Drs. Simón Pérez Alva y Guillermo Feldmuth, en la Facultad de Farmacia y Bioquímica. Coincidentemente, llegó a Lima para ofrecernos un ciclo de conferencias el Maestro A. R. Prevot, Jefe del Servicio de Anaerobios del Instituto Pasteur de París, donde había estudiado el Dr. Pérez Alva. Recuerdo bien las exposiciones del Dr. Prevot sobre el Sistema de Clasificación Bacteriana que el había creado. El Sistema Prevot (1940-1961), tenía como base elementos tomados de la citología y de la fisiología, por lo cual lo denominaba Clasificación con Base Citofisiológica. Años después, en 1962, en mi condición de becario en el mencionado Instituto parisino, tuve la oportunidad de recibir en el Servicio del Dr. Prevot las enseñanzas de sus discípulos Dr. Veron y Mlle. Sebald, a través de las que pude conocer, de primera fuente, que ellos estaban reclasificando el género Vibrio para convertirlo en el género Campylobacter; investigación que fue publicada en 1963

En este género, tiempo después, se incluyó (sugiero: incluyó al) Vibrio rugula como Campylobacter pyloridis, rebautizado posteriormente como $\mathrm{C}$. pyloris y, tiempo después (sugiero: y luego, finalmente), como Helicobacter pylori. Es precisamente con esta bacteria que aconteció otro muy interesante caso de "Serendipia y Microbiología", pues desde muchos años atrás, al observar cortes histológicos de mucosa gástrica, se veían unas formas bacilares, al parecer bacterianas, pero se pensaba que en un $\mathrm{pH}$ tan ácido no podían crecer o sobrevivir las bacterias; sin embargo, se intentaba aislarlas, fracasando en múltiples intentos. Pero fue en 1981, cuando el Dr. Warren, en Australia, reinició sus investigaciones, esta vez en cooperación con el Dr. Marshall, empleando diversas técnicas alternativas para aislar el microorganismo que, en 1979, había observado en el estómago de pacientes con úlceras. Finalmente en 1982, luego que distraídamente olvidaron, durante cinco días,en las incubadoras, unas placas de Petri sembradas previamente, en ocasión de las vacaciones por Semana Santa, al regresar, observaron el desarrollo de colonias que correspondieron, una vez hechos los estudios confirmatorios, a Helicobacter pylori. Este es otro caso de Serendipia y Microbiología que valdría la pena volver a describir detalladamente en otro artículo.

El Dr. Hernández nos ha contado una anécdota, pero hecho científico que merece ser incorporado como otro de los grandes ejemplos de Serendipia y Microbiología. 
Relata el Dr. Hernández que pocos años ha, inició un trabajo de investigación en una región volcánica de Costa Rica cuyo objetivo principal era el estudio de la biodiversidad extrema. Para ello, tenían que hacer distintos análisis para poner en evidencia los microorganismos que viven en esos ambientes inhóspitos y su tarea, como microscopista electrónico, era hacerlo mediante micrografías. El primer día en la región, acompañado de su colega la Dra. Ana Sittenfeld, coordinadora de dicho (sugiero: del) proyecto, quien le mostraría la región para qué evaluara que muestras y acciones debía tomar en el futuro trabajo, una de las cosas que más lo sorprendió fue la existencia de comunidades microbianas endolíticas esto es que viven dentro de las rocas. Obviamente, de inmediato el Dr. Hernández sacó una navaja y comenzó a recoger algunas muestras, pero su colega le indicó que no era necesario, pues eso estaba descrito, se trataba de comunidades de un alga Cyanidium caldarium e incluso se tenían fotos al microscopio electrónico. Sin embargo, buen científico al fin, el Dr. Hernández siguió tomando las muestras y las llevó consigo. Días después en el laboratorio, cuando se disponía a procesar una serie de muestras, tomó los fragmentos de roca para estudiarlos pero, realmente como tenía mucho trabajo y ante el recuerdo de que eso ya estaba descrito, decidió procesarlos por un método rápido, que sólo incluía someter las muestras a vapores de osmio y secarlas al horno, fijarlas por inmersión, deshidratarlas y secarlas mediante un proceso que evitara el colapso de las estructuras biológicas delicadas. Al observarlas, su sorpresa fue mayúscula pues, en vez de las algas esperadas, había una gran cantidad de diatomeas.

Ha resultado que se trata de la primera descripción de diatomeas como organismos endolíticos y posiblemente se trate de dos especies nuevas del género Pinnularia.

Como se puede apreciar, por un simple hecho de Serendipia descubrieron las diatomeas. Posiblemente, si hubiesen procesado las muestras por el método estándar, habría encontrado una gran cantidad de Cianidios que hubiesen enmascarado las diatomeas. Al procesarlas, secando al horno, se colapsaron las células esferoides de Cianidios, y las diatomeas, por tener un esqueleto de sílice, no colapsaron y fueron muy evidentes.
Estos pocos, pero valiosos ejemplos, demuestran como la Serendipia ha estado vinculada a grandes avances en Microbiología, gracias, por supuesto, a que los protagonistas de los descubrimientos estaban bien preparados en investigación científica. Esperemos que descubrimientos de esta clase sigan apareciendo, para bien de la Ciencia y la Humanidad. $\infty$

\section{Bibliografía y Consultas efectuadas}

Hernández-Chavarria F, Rivera P. Serendipia e investigación en microbiología. Rev Col de MQC de Costa Rica 2011; 8(1): 6-11.

2. Hernández-Chavarría F. Comunicación personal, 2006.

3. Zarzuelo A. Discurso de Incorporación a la Academia Iberoamericana de Farmacia, Granada, 2005.

4. Sebald M, Veron M. Teneur en bases de 1'ADN et classifications des vibrions. Annales de l'Institut Pasteur 1963; 105: 897-910,

5. Prevot AR. Classification des bacteries, 29 lección en el curso de microbiología 19611962. Instituto Pasteur de París: p163- 69. y Notes Techniques por M. Veron p171-74.

6. Marshall BJ, Warren JR. Unidentified curved bacilli in the stomach of patients with gastritis and peptic ulcerations. The Lancet 1984; 1(8390): 1311-5. 